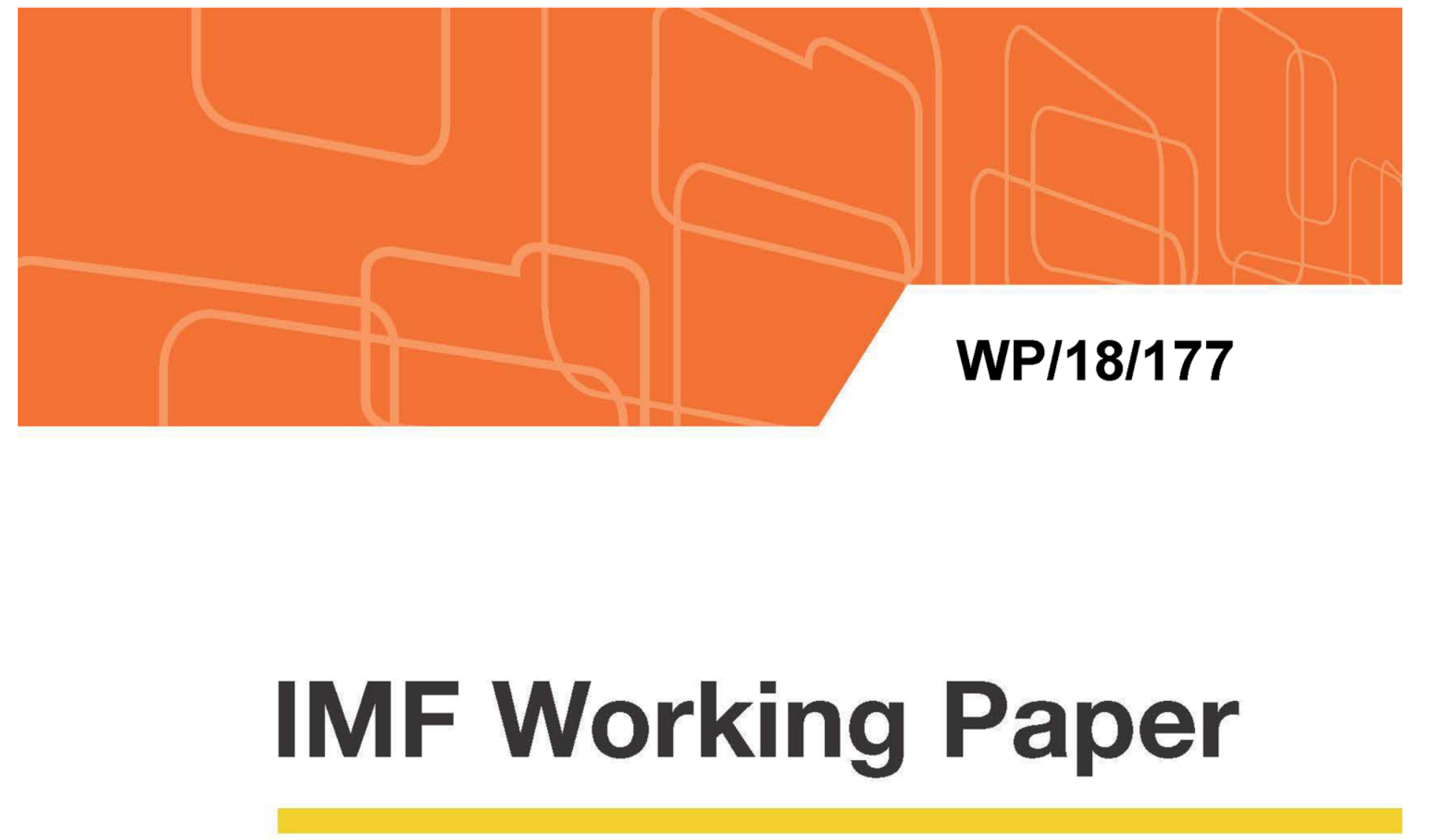

\title{
Inflation Expectations Anchoring Across Different Types of Agents: the Case of South Africa
}

by Ken Miyajima and James Yetman

IMF Working Papers describe research in progress by the author(s) and are published to elicit comments and to encourage debate. The views expressed in IMF Working Papers are those of the author(s) and do not necessarily represent the views of the IMF, its Executive Board, or IMF management. The views in this paper also do not necessarily reflect those of the BIS.

$$
\text { I N T E R N A T I O N A L M O N E T A R Y FU N D }
$$




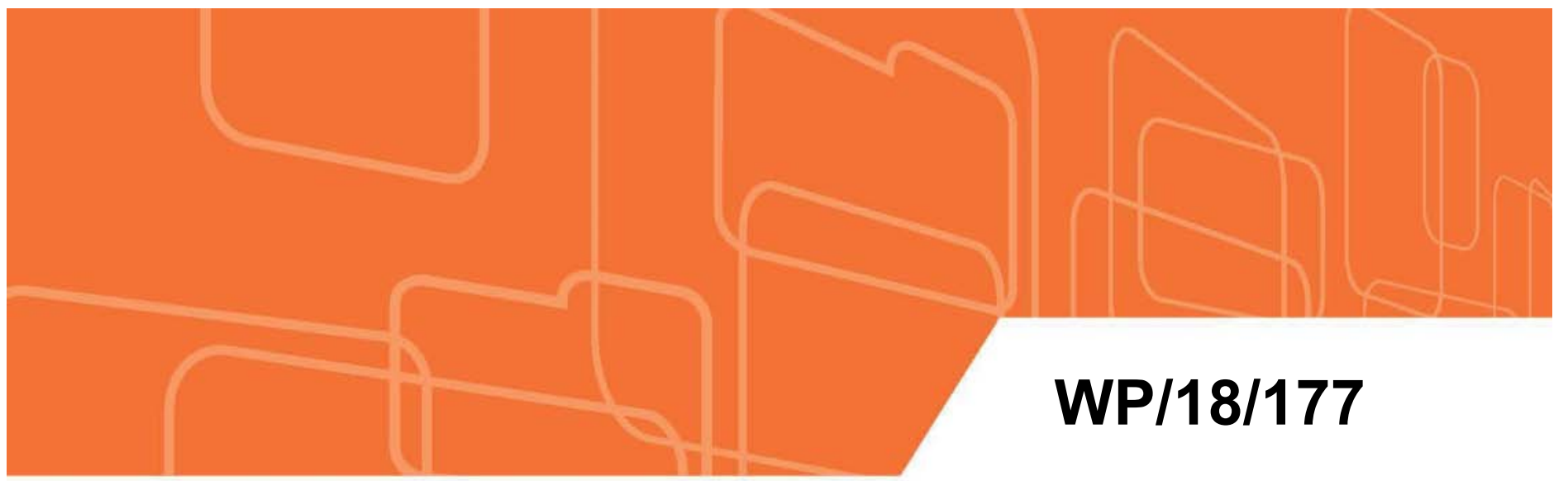

\section{IMF Working Paper}

\section{Inflation Expectations Anchoring Across Different Types of Agents: the Case of South Africa}

by Ken Miyajima and James Yetman

IMF Working Papers describe research in progress by the author(s) and are published to elicit comments and to encourage debate. The views expressed in IMF Working Papers are those of the author(s) and do not necessarily represent the views of the IMF, its Executive Board, or IMF management. The views in this paper also do not necessarily reflect those of the BIS. 


\title{
IMF Working Paper
}

\author{
African Department \\ Inflation Expectations Anchoring Across Different Types of Agents: \\ the Case of South Africa \\ Prepared by Ken Miyajima and James Yetman \\ Authorized for distribution by Ana Lucía Coronel
}

August 2018

\section{IMF Working Papers describe research in progress by the author(s) and are published to elicit comments and to encourage debate. The views expressed in IMF Working Papers are those of the author(s) and do not necessarily represent the views of the IMF, its Executive Board, or IMF management. The views in this paper also do not necessarily reflect those of the BIS.}

\begin{abstract}
Inflation forecasts are modelled as monotonically diverging from an estimated long-run anchor point, or "implicit anchor", towards actual inflation as the forecast horizon shortens. Fitting the model with forecasts by analysts, businesses and trade unions for South Africa, we find that inflation expectations have become increasingly strongly anchored. That is, the degree to which the estimated implicit anchor pins down inflation expectations at longer horizons has generally increased. Estimated inflation anchors of analysts lie within the 3-6 percent inflation target range of the central bank. However, the implicit anchors of businesses and trade unions, who are directly involved in the setting of wages and prices that drive the inflation process, have remained above the top end of the official target range. Possible explanations for these phenomena are discussed.
\end{abstract}

JEL Classification Numbers: E31, E58

Keywords: decay function, inflation anchoring, inflation expectations, inflation targeting. Author's E-Mail Address: KMiyajima@imf.org; James.Yetman@bis.org 


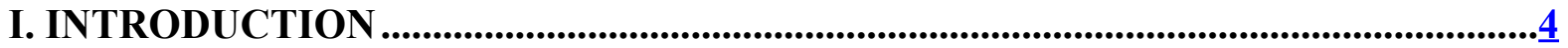

II. INFLATION AND INFLATION EXPECTATIONS ............................................6

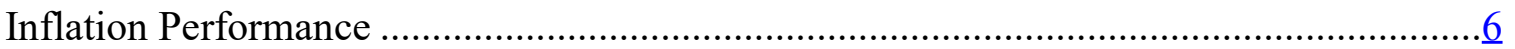

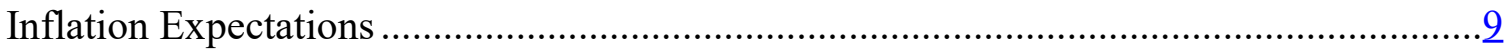

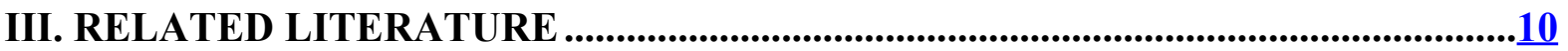

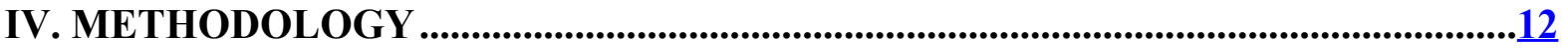

V. THE DATA

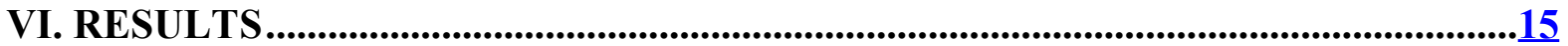

The Weight on the Implicit Anchor in Explaining Inflation Expectations ......................17

Different Forecast Horizons.................................................................................. 17

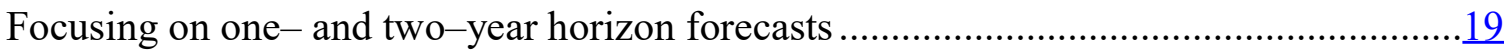

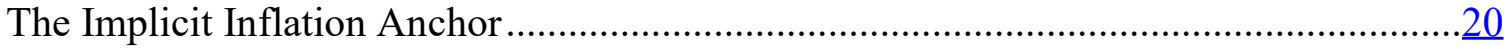

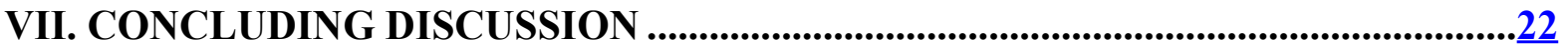

\section{Figures}

1. Headline Inflation and Official Inflation Target Range ..............................................

2. Indicators of South Africa's Inflation Performance..................................................

3. Inflation Expectations and Inflation Target Range ..................................................

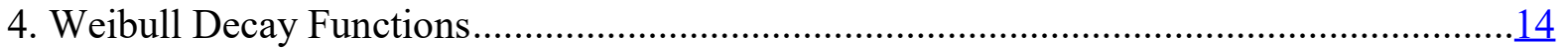

5. Weight on Anchor Over Different Forecast Horizons, Consensus Forecasts.....................17

6. Weight on Anchor Over Different Forecast Horizons, BER Expectations .......................18

7. Weight on Anchor 12 And 24 Months Ahead, Consensus Forecasts ...............................19

8. Weight on Anchor Four and Eight Quarters Ahead, BER Expectations ..........................20

9. Estimated Inflation Anchor Using Consensus Economics Forecasts ...............................20

10. Estimated Inflation Anchor Using BER Expectations ..........................................

11. Inflation Forecast Mean Squared Error ................................................................

\section{Tables}

1. Inflation Facing Different Expenditure Quintiles in South Africa, 2009M01-2017M12 .....

2. Estimation Results .......................................................................................

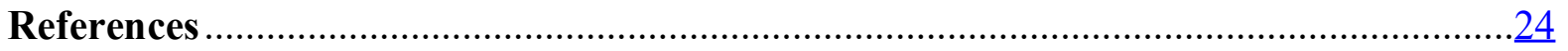




\section{INTRODUCTION ${ }^{1}$}

Well anchored inflation expectations are considered to be a key indicator of a highly credible central bank. They can increase the potency of monetary policy and contribute to stable inflation outcomes. In addition, they offer positive fiscal spillovers: low and stable expected inflation contributes to reducing risk premia in interest rates that a country pays when borrowing funds, and hence debt management costs. ${ }^{2}$

Much existing work on inflation expectations has focused on the expectations of financial analysts or professional forecasters. This literature has highlighted that central bank communications can be a powerful monetary policy lever (eg Gürkayak et al., 2005). But the expectations of financial analysts and professional forecasters are not the only, or even necessarily the most important, expectations from the point of view of the central bank seeking to understand inflation dynamics, since they do not themselves contribute a large share of economic activity. While the published inflation expectations of financial analysts may affect those of other economic agents, the strength of the transmission channel between them is an empirical question. For some purposes, what might matter more are the expectations of the general public (Haldane and McMahon, 2018), or agents who are actively involved in the negotiation or setting of wages and prices, who thereby have a direct effect on inflation outcomes. These agents would include non-financial firms and trade unions. In collective bargaining, industry negotiators and unions would be expected to incorporate their expectations into their bargaining positions for multi-year wage agreements. This is particularly important in South Africa, where wage agreements between large unions and businesses through a centralized wage settlement process are then imposed on small- and medium-sized enterprises and other firms and affect the majority of the labour market. However, measures for the expectations of those who set prices charged by non-financial firms or who engage to collective bargaining are rarely available (Tarullo, 2017).

One important innovation in this paper is that we focus on inflation expectations for different agents for one country for which comparable data is available: South Africa. Forecasts of inflation are collected by the Bureau for Economic Research (BER) at Stellenbosch University for three sets of agents: analysts (who are much like the professional forecasters

\footnotetext{
${ }^{1}$ Miyajima is Senior Economist at the International Monetary Fund, 700 19th St NW, Washington DC, United States, kmiyajima@imf.org. Yetman is Principal Economist at the Bank for International Settlement Representative Office for Asia and the Pacific, 78th Floor, Two International Finance Centre, 8 Finance Street, Central, Hong Kong, james.yetman@bis.org. We are grateful to the staff of the South African Reserve Bank and Bureau of Economic Research South Africa for providing data and guidance. We thank, without implication, Ana Lucía Coronel, Hèndré Garbers, Gaston Gelos, Federico Grinberg, Thomas Harjes, Aaron Mehrotra, Montfort Mlachila, Chris Papageorgiou, Axel Schimmelpfennig, Filiz Unsal, Holly Wang and the participants of the 2018 IMF Article IV Consultation Workshop, in particular Rudi Steinbach as discussant, and the African Department Monetary Policy Network seminar for helpful comments. The views expressed here are those of the authors, and are not necessarily shared by the Bank for International Settlements or the International Monetary Fund.

${ }^{2}$ The relationship may also work in reverse: improved fiscal conditions tend to lead to lower inflation expectations (Celasun et al, 2004).
} 
typically examined elsewhere), businesses and trade unions. The latter two categories represent agents whose expectations directly affect inflation dynamics via wage and price setting decisions. ${ }^{3}$

Actual inflation is subject to persistent shocks that drive inflation away from any anchor point, complicating the assessment of how well anchored inflation expectations are. One solution to this problem is to assess anchoring by means of long-run inflation expectations, beyond the horizon where persistent shocks might have a noticeable effect. Previous studies have addressed this based on either long-run inflation surveys or break-even inflation rates drawn from the prices of assets with long maturities. But neither of these solutions is idealthe former are generally published infrequently and for a limited number of economies, while the latter are influenced by many factors other than inflation expectations (eg, trading liquidity of inflation-linked bonds) and are too volatile to be plausibly interpreted as long-run inflation expectations (Faust and Wright, 2013).

To assess the anchoring of inflation expectations for South Africa, we estimate the inflation anchor that is implied by short-to-medium term inflation forecasts, following the methodology introduced by Mehrotra and Yetman (2014b). The approach is motivated by the idea that inflation forecasts made sufficiently far in advance may be anchored at a level that bears little relationship with actual inflation-both at the time that the forecast is made and for the period being forecast. For inflation targeting (IT) economies, the level of the implicit inflation anchor could correspond to the central bank's inflation target. But it could also be influenced by other factors, especially if the central bank lacks credibility. Regardless, as the forecasting horizon shortens, any role that the implicit inflation anchor plays in affecting inflation forecasts is likely to decrease as forecasters learn more about the realization of shocks that will affect inflation in a given period. Our modelling strategy allows for all these possibilities by fitting forecasts with a model based around a decay function, where the weight on the long-run anchor decreases monotonically with the forecast horizon.

This approach allows us to assess the extent of anchoring from two angles-(i) the weight on the implicit inflation anchor in determining inflation expectations and (ii) the level of the anchor itself. For instance, economic agents could become increasingly forward looking in setting their inflation expectations by assigning a greater weight to their implicit inflation anchor (and a correspondingly smaller weight to actual inflation), leading to more strongly anchored expectations. However, if the level of the implicit inflation anchor is higher than the level targeted by the central bank, observed inflation expectations will tend to be higher as well.

Inflation expectations in South Africa have tended to stay high relative to the inflation target range, and at times relative to inflation outcomes as well. Our model attributes this in large part to the implicit inflation anchor remaining high. We find that the behaviour of the estimated anchor varies across the different types of forecasters. For analysts, implicit inflation anchors lie within, though towards the upper end of, the central bank's target range. But for businesses and trade unions, implicit inflation anchors remain consistently above the

\footnotetext{
${ }^{3}$ Short horizon expectations of households are also collected, but are not examined here.
} 
upper end of the target range. Additionally, the weight on the anchor (that is, the degree to which forecasts are explained by the anchor) has generally increased over time, although it is higher for analysts than for businesses and trade unions.

So, what could explain the differences between analysts on the one hand, and businesses and trade unions on the other? Expectations of average inflation reported by some businesses and trade unions may be biased upwards because different agents face different effective inflation outturns, with less affluent households often facing higher inflation then more affluent ones (as we will show in the next section). However, we suspect businesses and trade unions in the BER surveys are unlikely to belong to expenditure deciles facing meaningfully aboveaverage inflation outturns, at least on average. In addition, we find that inflation expectations of businesses and trade unions are more backward-looking than analysts. Perhaps their inflation expectations are influenced by the growth rate of wages, which has remained higher than the average inflation rate.

Put another way, the inflation expectations' anchoring of the two types of domestic agents involved in wage and price setting - businesses and trade unions - are more similar to each other than to analysts. For both, anchoring remains relatively weak, and the implicit anchors generally exceed the target range by a similar magnitude. One intriguing possibility that could help explain this is that the expectations of both types of agents are influenced by each other, perhaps during the negotiations between them to set wages. Another possible explanation for the weaker anchoring of the expectations of businesses and trade unions visà-vis analysts is that analysts pay greater attention to inflation developments, and their expectations have hence reacted more strongly to the introduction of IT. Thus, as inflation rates have declined and stabilised, the expectations of analysts may have responded faster, resulting in greater apparent anchoring. Regardless of the explanation, the South African forecast data illustrates that the challenges of anchoring inflation expectations vary across different types of agents.

This paper is structured as follows. The next section discusses the institutional background of IT in South Africa, and related issues. Section 3 summarises the related literature. Section 4 presents the methodology, and evaluates its suitability for assessing the behaviour of inflation expectations. Section 5 discusses the data and section 6 presents the empirical results. Finally, section 7 concludes.

\section{INFLATION AND INFLATION EXPECTATIONS}

This section discusses the behaviour of inflation and inflation expectations in South Africa.

\section{Inflation Performance}

Recent decades have been characterized by a trend decline in inflation in South Africa, starting long before the introduction of IT (Figure 1). During this period, monetary policy had many guises. Interest rates first played a pivotal role after direct monetary controls were 
replaced with market-based monetary policy in $1980 .^{4}$ Inflation fluctuated in the rage of 1020 percent from then until the early-1990s. It then dropped, registering single-digit outturns for the first time in almost a decade at the end of 1992. The average inflation rate during 1993-99 fell further, to around 8 percent. During this period, exchange controls were gradually abolished.

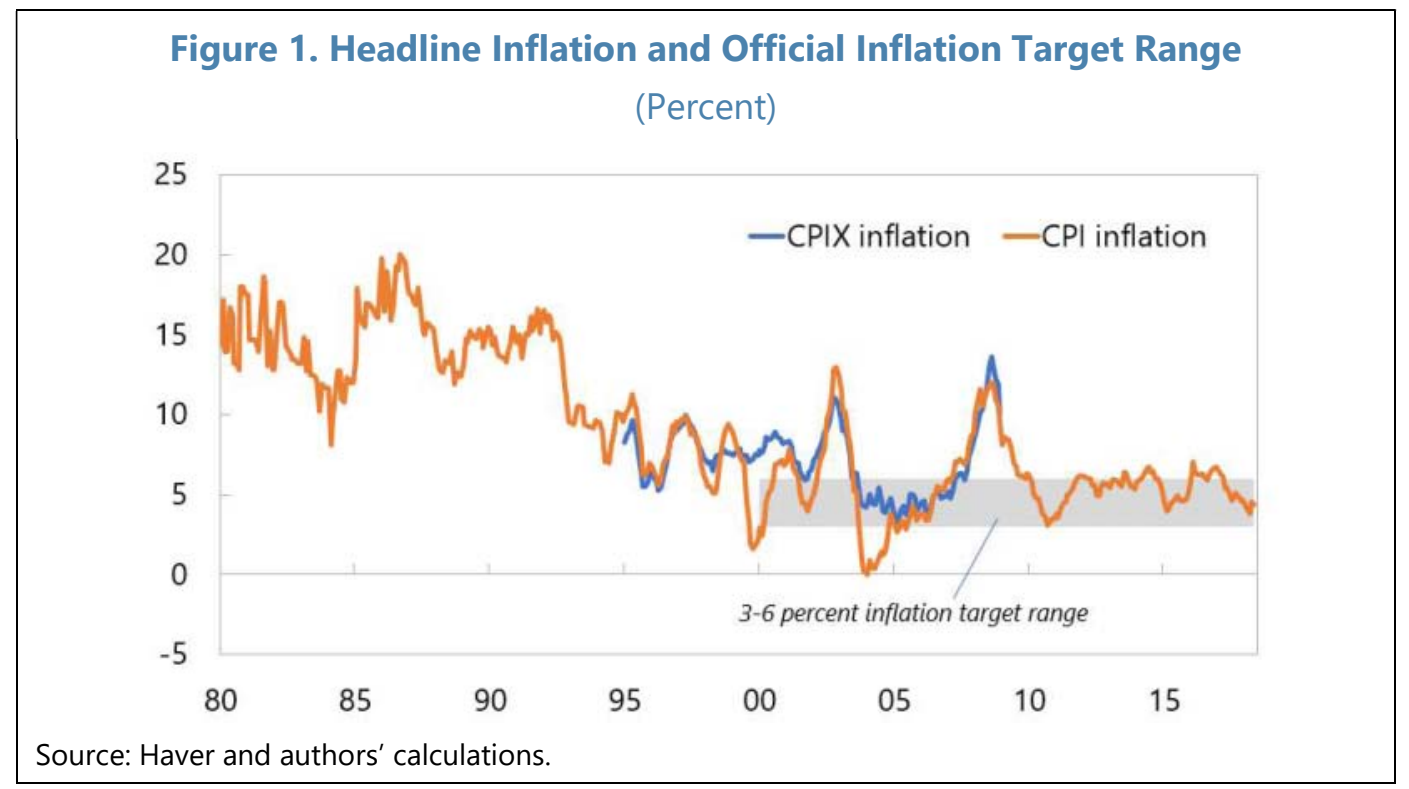

Inflation remained volatile after the inception of IT but has become more stable in the past decade, concentrated around the upper end of the 3-6 percent target range. The intention to adopt IT was first announced in August 1999. Originally, the authorities planned to narrow the target range from an initial 3-6 percent in 2002-03 to 3-5 percent beginning in 2004-05. However, the rand weakened sharply and inflation spiked towards the end of 2001, and the planned change did not take place. ${ }^{5}$ Inflation rose again in 2008 on higher commodity prices and subsequently fell to the lower end of the target range. In 2009, the reference inflation rate for the IT changed from the CPIX (CPI less the interest on mortgage bonds) to the CPI. ${ }^{6}$

${ }^{4}$ The South African Reserve Bank (SARB) was established in 1921. By the middle of the 1960s, credit controls, credit ceilings and deposit rate control were adopted. After the end of the Bretton Woods agreement in 1971, South Africa pegged or managed the currency, called the rand. The rand was pegged to the pound sterling, the US dollar, a basket of currencies, and again to the US dollar, in turn. The rand was formally devalued twice, in December 1971 and September 1975. A managed floating regime was introduced in January 1979. The money supply growth targets adopted in 1986 were replaced with money supply growth guidelines in the early-1990s. In 1995, the financial rand, an investment currency for non-residents, was abolished. This was followed by the gradual relaxation of exchange controls on residents.

${ }^{5}$ See a public lecture by Governor Kganyago (2016): “The Influence of South Africa's Price-setting Environment on Monetary Policy Trajectory." Available at https://www.bis.org/review/r160908a.pdf

${ }^{6}$ Despite the target having been changed from CPIX to CPI inflation, we focus on CPI inflation throughout as CPI inflation expectations have been surveyed consistently since 2000 by BER and since 1993 by Consensus Economics. BER stopped surveying CPIX inflation expectations when the official inflation target was changed to CPI inflation. 
Since 2010, inflation has remained close to the upper end of the target range, before moderating toward the mid-point over the past year, aided by significant crop food price disinflation and exchange rate appreciation.

While South Africa's inflation has declined and become more stable in recent decades, its performance lagged global disinflation trends over the last 10 years (Figure 2). In recent data, South Africa's inflation rate is among the highest 25 percent of economies across the globe, and it has declined by less than many of its trading partners. Average inflation in the emerging economies to which South Africa exports its products declined from 7 percent in 2000-02 to around 5 percent in 2017; comparable statistics for advanced export destinations indicate inflation broadly unchanged at around 2 percent. During the same period, inflation in South Africa remained stable at around 6 percent.

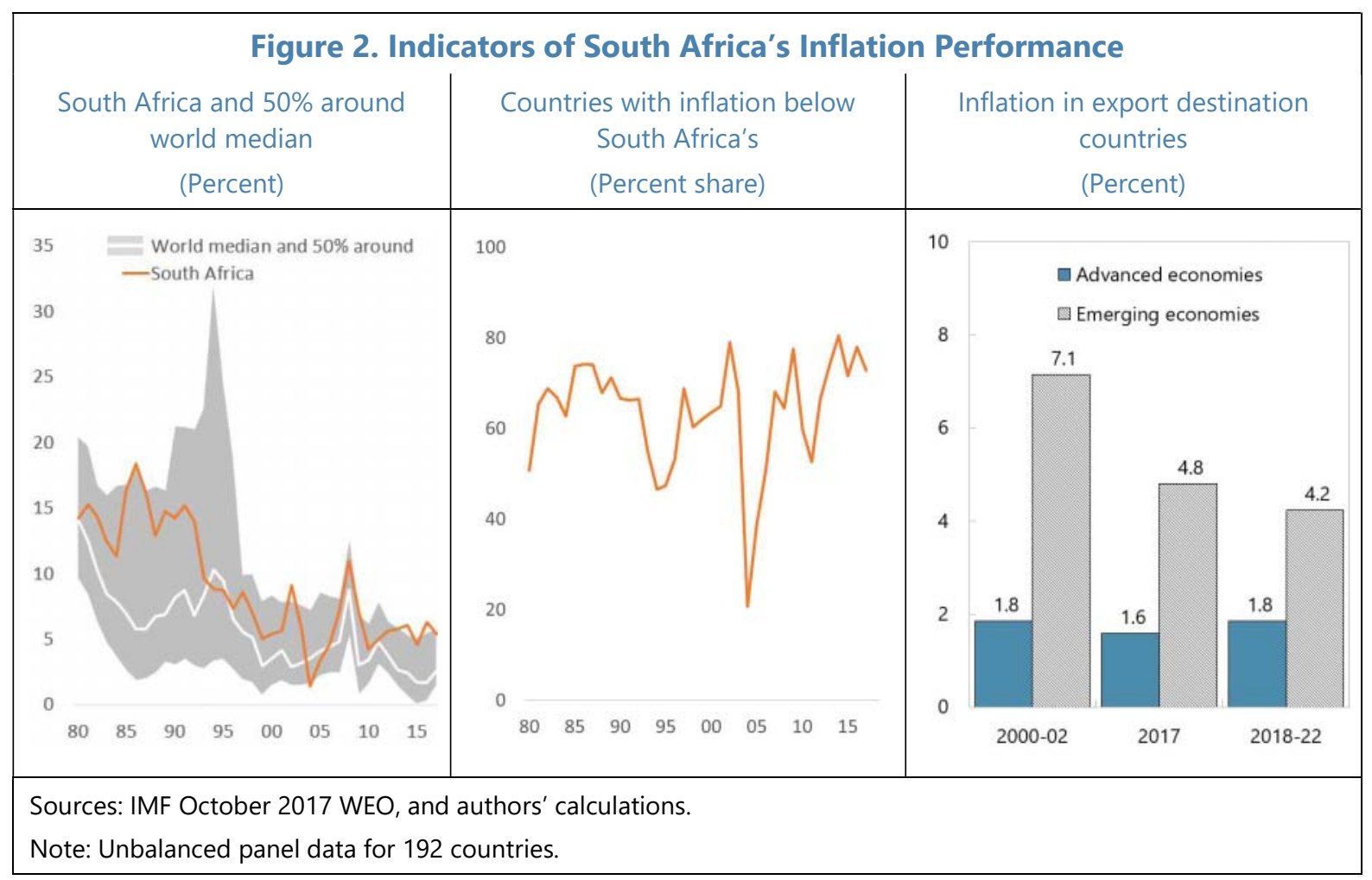

Less affluent consumers in South Africa tend to face higher inflation in terms of both level and volatility. Table 1 shows inflation statistics for different expenditure quintiles. The first row shows that consumers in the lowest quintiles tend to face the highest inflation in general. The second row shows that, in any given month, the probability that the consumers in the lowest quintile face the highest inflation among different quintiles is 56 percent, by far the highest compared to the other quintiles. The third row shows that this tends to happen when overall inflation is high, or the economy is in a "high inflation" regime. For instance, the average inflation during the months the lowest quintile faces the highest inflation is 7 percent, one of the highest among the five expenditure quintiles. This is due partly to the fact that food prices account for 35-40 percent of the CPI basket for the lowest expenditure quintile, almost four times the share for the highest expenditure quintile. 
Table 1. Inflation Facing Different Expenditure Quintiles in South Africa, 2009M01-2017M12 (Percent)

\begin{tabular}{lrrrrr}
\hline Expenditure Quintile & 1 & 2 & 3 & 4 & 5 \\
\hline Average inflation & 6.1 & 6.0 & 5.9 & 5.8 & 5.4 \\
Probability of facing highest inflation & 56 & 7 & 4 & 6 & 22 \\
Average inflation, given particular quintile faces highest inflation & 7.0 & 8.3 & 6.7 & 5.4 & 5.1 \\
\hline
\end{tabular}

Sources: Stats SA and authors' calculations.

\section{Inflation Expectations}

Inflation expectations are an important input into monetary policy decisions because inflation expectations influence price and wage setting decisions and therefore inflation outcomes. To that end, the SARB commissioned the BER in 2000 to conduct a quarterly inflation expectations survey among households, financial analysts, business people and trade union officials. Inflation expectations are surveyed for the current year, the next year, two years ahead and the average over the coming five years. Data from these surveys are central to the analysis of this paper, and are displayed in Figure $3 .^{7}$

The survey results show that inflation expectations across the different types of economic agents are heterogeneous in South Africa. Expectations of analysts appear to be relatively stable, and generally lie within the official target band, especially at longer horizons. Those of agents constituting a significant share of economic activity, that is, households, businesses and trade unions, are more volatile and generally slightly above the upper end of the target band. Recently, inflation expectations fell markedly, reflecting favourable inflation outturns and perhaps anticipation of structural reform implementation.

Note that two-year-ahead inflation expectations, especially for analysts, appear to be less volatile than their one-year-ahead expectations. In our modelling approach, this will be explained by longer horizon expectations being more strongly anchored than their shorter horizon counterparts.

One possible explanation for the differences between analysts and others is that businesses and trade unions could be more backward looking, perhaps in part on account of relatively inflexible labour markets. In addition, wage adjustments have often exceeded inflation, and by amounts that do not seem consistent with productivity, complicating the task of the SARB to achieve its inflation objective without generating large output costs. On average, nominal wages grew by close to 10 percent annually during 2012-17, while labour productivity growth was only $1-1.5$ percent. ${ }^{8}$ This suggests that supply factors may have dominated

\footnotetext{
${ }^{7}$ Inflation expectations of households are only surveyed for the current year. Hence, we do not include them in our estimation.

${ }^{8}$ Total non-agricultural wages and non-agricultural labour productivity.
} 
demand factors in driving South African inflation dynamics. Relatedly, empirical estimates of the South African Phillips curve suggest that it is relatively flat (Kabundi et al., 2016).

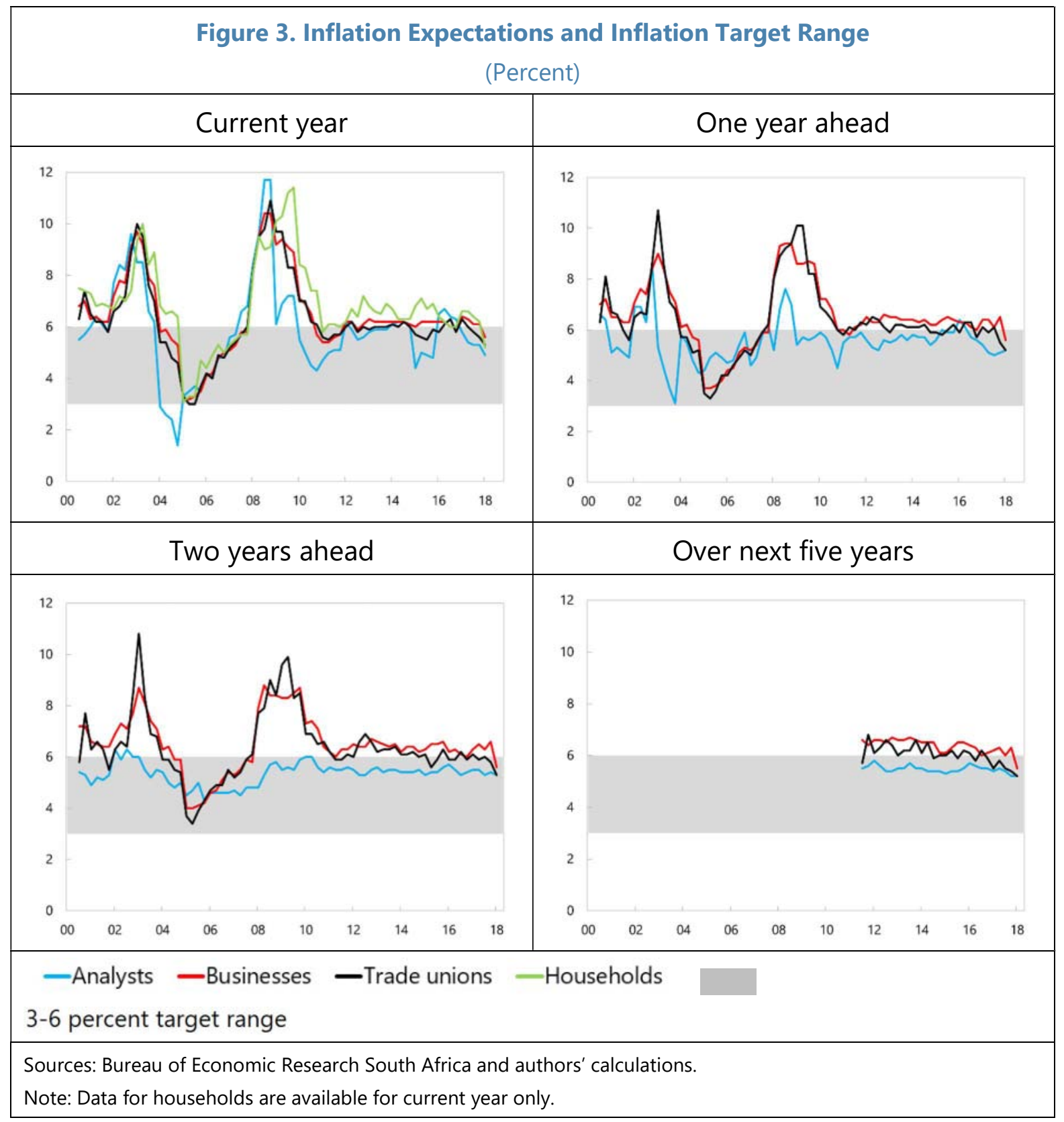

\section{RELATED LITERATURE}

The implicit anchor of inflation expectations for South Africa has been estimated using several different approaches in previous studies. Klein (2012) estimates the implicit anchor for the period 2001Q1-11Q4 by applying a state-space approach to a Taylor-type rule since the adoption of IT. He finds that the implicit inflation anchor tends to be in the upper half of the inflation target band for most of the time through the global financial crisis (GFC), and at around the upper end of the inflation target band after the GFC. The author suggests that the 
results can be explained by the view that the SARB might have become more tolerant of higher inflation following the GFC. The results are based on Reuters Econometer Consensus survey of inflation expectations of analysts, and did not consider expectations of other types of agents. Note that the estimates of the anchor using this approach are conditional on the estimated output gap and natural interest rate used in their derivation.

In another representative work on South Africa, Kabundi et al (2015) uncover the implicit inflation anchors for different agents by estimating reduced form models of inflation expectations. In their model, inflation expectations are a function of past inflation and an unobserved inflation target, similar in spirit to our approach. Estimating the model with OLS for 2001Q1-2013Q1, the authors find that the implicit inflation anchors of businesses and trade unions are 6.8 percent and 6.6 percent, above the upper end of the official target band. By contrast, for analysts, the implicit inflation anchor of 5.4 percent remains within the band. Their results illustrate that inflation expectations are heterogeneous, and suggest that those of domestic wage and price setters contribute to elevated inflation expectations at the aggregate level. One way to extend their paper is to analyse the time series dynamics of the implicit inflation anchors, which we do.

Models of inflation expectations based on decay functions, where inflation expectations increasingly diverge from an anchor towards recent inflation outcomes as the forecast horizon shortens, are used to estimate the implicit inflation anchor for a wide range of economies (but not including South Africa) in Mehrotra and Yetman (2014b). They show that their model fits the data well, and provides simple estimates of the degree to which inflation expectations are anchored.

Applying the same model to forecaster-level data in Canada and the United States, Yetman (2017) finds that the economy with a long history of explicit IT (Canada) has more tightly anchored expectations than the one where there was no explicit numerical inflation target before 2012 (the United States). Similarly, applying the model to forecaster-level data in Japan, Hattori and Yetman (2017) find that the degree to which implicit inflation anchors pin down inflation expectations at longer horizons has increased but remains considerably lower than Yetman (2017) found for either Canada or the United States.

This paper is also related to studies of expectations that examine forecasts from different types of economic agents. An early such paper was Carroll (2003) who examined household inflation expectations in the United States from the Michigan survey relative to professional forecasts from the Federal Reserve Bank of Philadelphia's "Survey of Professional Forecasters". He found that, while household inflation expectations are not rational, they can be derived from the more rational professional forecasts. Madeira and Zafar (2015) use the panel component of the Michigan Survey of Consumers and find that a segment (women, ethnic minorities, and less educated agents) of the surveyed population has a higher degree of heterogeneity in their idiosyncratic information and that these agents attached smaller weights to recent movements in inflation when forming inflation expectations.

For related studies focused on other countries, Gaglianone (2017) surveys the empirical evidence on inflation expectations in Brazil and argues that better-performing forecasters tend to update their forecasts more often and influence other forecasters' expectations in turn, 
while consumers' inflation expectations are strongly influenced by inflation outturns. Łyziak (2015) finds that the inflation target of the National Bank of Poland has a strong impact on the inflation expectations of financial sector analysts but a relatively small impact on consumers' inflation expectations. Meanwhile, Coibion et al (2018) find that firms in New Zealand display diverse expectations about inflation that are much higher on average than professional forecasters, despite inflation targeting having been in place for 25 years.

Two studies of inflation expectations for different types of agents for South Africa use data from the same source of our study. Kabundi et al (2015) focus on forecasts for analysts, businesses and trade unions and find that inflation expectations are heterogeneous. Pierdzioch et al (2018) report that forecasts contain information about the subsequent directional change in inflation outcomes.

This paper adds to the literature in at least three ways. First, we extend the existing work on South Africa by using a model of inflation expectations based on a decay function to estimate both the weights on the implicit inflation anchor and its level across time. Second, we assess changes in the implicit inflation anchor in the period prior to the introduction of IT by using inflation expectations of analysts going back as far as 1993. Third, we extend Kabundi et al (2015) to disentangle heterogeneous inflation expectations, across different types of economic agents, over time.

\section{Methodology}

We adopt the parsimonious framework for fitting inflation forecasts introduced in Mehrotra and Yetman (2014b). This framework fully utilizes the multiple-horizon dimension of the available forecast data. It assumes that, if inflation expectations are well anchored at a particular level, inflation forecasts made sufficiently far in advance should be centred on their anchor. Then, as the forecast horizon shortens and forecasters observe information that improves their ability to predict inflation outcomes, inflation expectations will start to deviate from their long-run anchor towards the level of actual inflation.

This approached is motivated by the behaviour of forecast data at different horizons. Mehrotra and Yetman (2014b) look at median inflation forecasts for a given period across different forecast horizons, with forecasts made from 24 months to 1 month before the completion of the calendar year being forecast. They focus on 44 economies, with a base sample period of 2005-12. They confirm that forecasts for different years look much alike at long forecast horizons, but start to deviate further from each other as the forecast horizon shortens, and, at very short horizons, look a lot like the distribution of inflation outcomes. The close resemblance between the 24-month-ahead forecasts for different years, during a time period that includes the GFC, is particularly striking in the case of the United States. Isiklar and Lahiri (2007) provide similar evidence regarding forecasts of GDP growth where forecasts are very similar at a 24-month horizon, and do not change very much at longer horizons when forecasts are updated each month.

Following Mehrotra and Yetman (2014b), the forecast of inflation for year $t$ made at horizon $h$, denoted $f(t, t-h)$, is assumed to follow: 
$f(t, t-h)=\alpha(h) \pi^{*}+[1-\alpha(h)] \pi(t-h)+\varepsilon(t, t-h)$.

In (1), $h$ is the forecast horizon, measured as the length of time remaining before the end of the year that is being forecast. ${ }^{9} \pi^{*}$ is the inflation anchor. $\pi(t-h)$ is the latest available level of inflation observed at the time when the forecast is made and $\varepsilon(t, t-h)$ is a residual term. The inflation forecast is of annual inflation (that is, the year-on-year-change in a 12month moving average of the level of the CPI); we compute $\pi(t-h)$ analogously for each month (or quarter using BER data) and then lag the series relative to the forecast date by one month (or quarter in the case of BER data) to allow for publication lag. This should also help to address any potential endogeneity issues between expected inflation and inflation outturns.

$\alpha(h)$ represents a decay function. As already discussed, this has the property that, as the horizon shortens, there is greater weight on realized outcomes and less on the long-run anchor point. In particular, we impose a functional form on $\alpha$ such that $\alpha(\infty)=1$ (the infinite horizon forecast of inflation is centred on the anchor) and $\alpha(0)=0$ (the forecast converges to the outcome as the forecast horizon goes to zero). We are agnostic on the exact form that the decay function should take, since it is likely to vary both over economies and over time. Ideally, we would therefore like a flexible functional form that can embrace a wide range of possible paths. We follow Mehrotra and Yetman (2014b) and consider:

$\alpha(h)=1-\exp \left(-\left(\frac{h}{b}\right)^{c}\right)$

This is based on the cumulative density function of the Weibull distribution. ${ }^{10}$ Figure 4 illustrates some of the wide variety of possible decay paths that this functional form can generate for different values of $b$ and $c$. With a small $b$ parameter, for example, the function remains near 1 until the horizon gets close to zero. By contrast, for a high $b$ parameter, $\alpha(h)$ may be far from 1 even at a horizon of 24. The $c$ parameter potentially provides the decay function with some shape. For example, when $b=6$, the function stays closer to 1 when $c$ is higher, but only at forecast horizons above 4 . Below that horizon, a higher $c$ implies a more rapid decline in $\alpha$.

\footnotetext{
${ }^{9}$ In some similar studies, the notation differs with forecasts made at time $t$ for time $t+h$. We use the notation here because our forecast panels are fixed-event: we have multiple forecasts of the event (inflation in a given year, indicated by $t$ ) made at different number of quarters before the completion of the year (indicated by $t-h)$.

${ }^{10}$ Mehrotra and Yetman (2014a) consider a more restricted version of the model (with $c=1$ ) for a group of Asian economies. We estimated the more restricted model on a portion of our samples and it was always rejected in favour of the more general model that we focus on.
} 


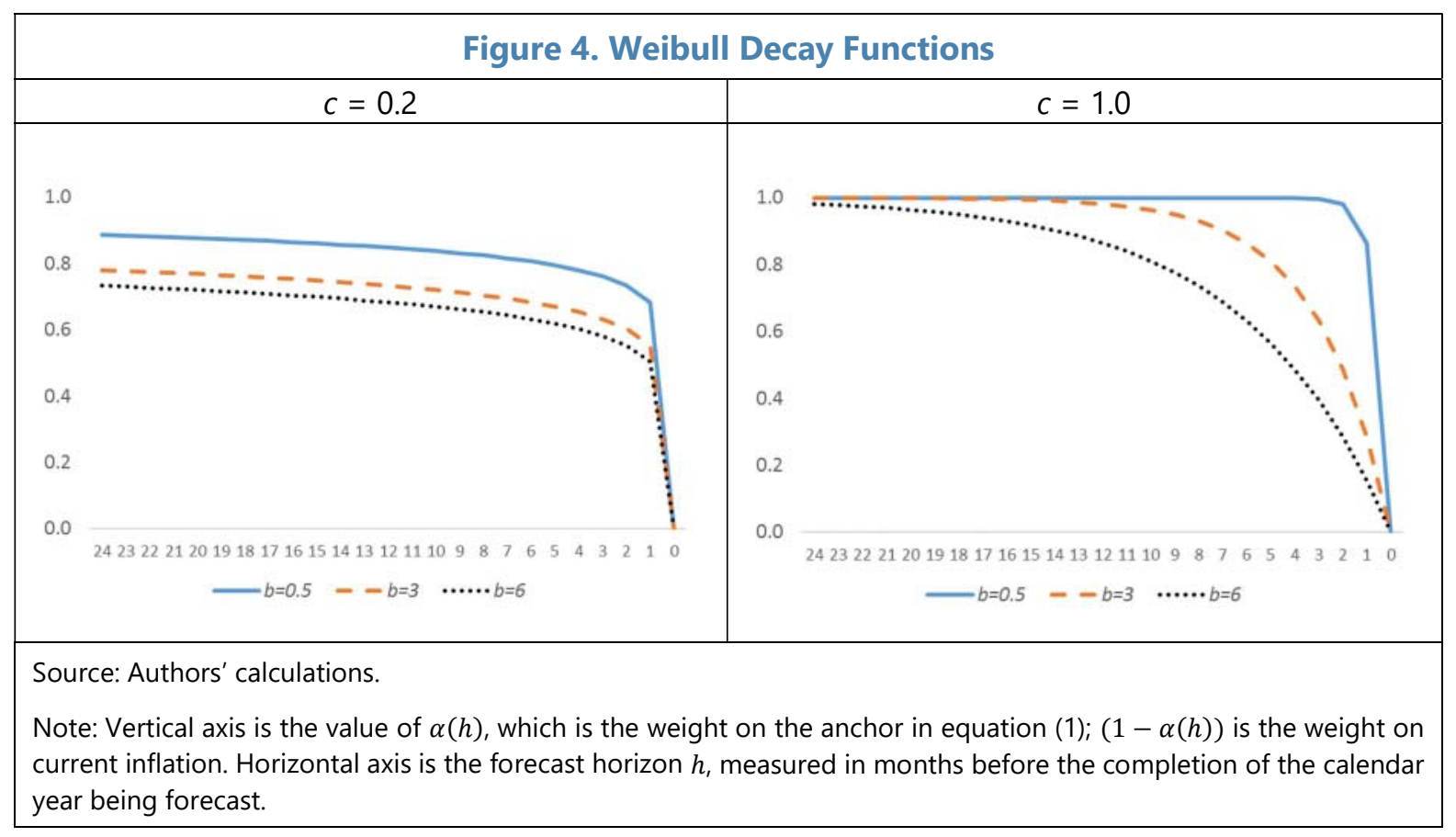

We can separately estimate the key parameters of the model $\left(b, c\right.$ and $\left.\pi^{*}\right)$ because of our assumption that the anchor, $\pi^{*}$, remains constant from one horizon to the next, whereas the value of the decay function, $\alpha(h)$, varies.

The variance of the residual in equation (1) is modelled using a flexible functional form that allows it to change with the forecast horizon with minimal restrictions as: ${ }^{11}$

$V(\varepsilon(h, t))=\exp \left(\delta_{0}+\delta_{1} h+\delta_{2} h^{2}\right)$.

Forecasts made at different horizons for the same inflation outcome are likely to be highly correlated, especially if the horizons are close together. We explicitly model this, assuming the correlation between residuals for forecasts of the same inflation rate, but made at two different horizons $h$ and $k$, is given by:

$\operatorname{Corr}(\varepsilon(t, t-h), \varepsilon(t, t-k))=\phi_{0}-\phi_{1}|h-k|$.

The model is estimated by maximum likelihood, considering a wide range of possible starting values and using the hill-climbing method of Broyden, Fletcher, Goldfarb and Shanno (see Shanno, 1985, for details), until the estimates converge.

\footnotetext{
${ }^{11}$ The use of the exponential function in equation (3) ensures that the fitted value of the variance is nonnegative at all horizons for all possible values of the parameters. We are not imposing any restrictions on how the residual variance varies as the forecast horizon shortens. It could be either increasing or decreasing, depending on how well the model fits the data at different horizons. This is in contrast to forecast error variability, which is likely to decrease monotonically as the forecast horizon declines (see Isiklar and Lahiri, 2007).
} 


\section{THE DATA}

We apply our model to two sets of survey-based CPI inflation expectations. Consensus Economics forecasts of inflation are available for 1993-17, with forecasts made monthly at horizons of up to 24 months. We also examine one and two-year ahead BER inflation expectations for analysts, businesses, and trade unions for 2001-17. ${ }^{12}$ These forecasts are made quarterly at horizons of up to 12 quarters (that is, the earliest forecast of 2017 inflation is made in January 2015). In principle, expectations in CPI could be less well anchored than those in CPIX during the period when the inflation target was specified in terms of CPIX rather than CPI (especially in the early party of the 2000s, when CPI inflation was more volatile than CPIX inflation).

As a robustness check, we also examine respondent-level BER inflation expectations (based on the individual forecast submissions by analysts, businesses, and trade unions), using a simplified version of our model (due to the highly unbalanced nature of the panel). CPI inflation is used as our measure of headline inflation. We estimate our model using 8-year rolling windows of the respective inflation expectations data.

The BER survey was designed using the Philadelphia Fed's Livingstone Survey and a similar one conducted by the Reserve Bank of New Zealand (RBNZ) as benchmarks. The selection of which groups of agents to cover were determined by the SARB's chief economist in coordination with the BER. The inclusion of trade unions is unique to this survey, and especially relevant given the structure of the South African labour market. At present, about 2500 adults are interviewed in the household survey. In contrast to the panel survey of analysts, business people, and trade unions, a new representative sample of households is put together in each quarter. The active number of respondents in the other categories are 34 analysts, 480 business people and 37 trade union representatives.

The BER inflation expectation data for South Africa are widely used. The SARB discusses the surveyed inflation expectations, with reference to agent-level information, in its MPC statements. The agent-level data have been used to gain better understanding of inflation dynamics by researchers, including Ehlers et al (2007), Rossouw et al (2011), Kabundi et al (2015) and Pierdziocha et al (2018).

\section{RESUlTS}

The estimates of the key parameters of our model and their standard errors are presented for a range of different samples in Table 2. At a glance, the estimates of the parameters are of similar magnitudes across the different samples, with the notable exception of $c$ for the

\footnotetext{
${ }^{12}$ Households are not included as data are available only for current year expectations. Average expectations over the next five years are not used as these are available for a very short period (beginning 2011), and are on a different basis than the other forecasts (the average inflation rate over a five-year period, rather than being for a specific future year). Given that expectations are likely to converge to the anchor as the horizon increases, average expected inflation over the next five years may be heavily influenced by short-term expectations, so is not necessarily for a longer effective average forecast horizon than two-year ahead forecasts. In our dataset, for example, average five-year expectations across all agents are more highly correlated with one-year ahead expectations (0.82) than two-year ahead expectations $(0.76)$.
} 
sample of trade unions, which is much higher than for other participants. As we will see, the combination of these different estimates across different types of agents will translate into differences in the degree to which expectations are anchored across forecast horizons.

\begin{tabular}{|c|c|c|c|c|c|c|c|c|}
\hline & Sample & $b$ & s.e. $(b)$ & $c$ & s.e. $(c)$ & $\pi^{*}$ & s.e. $\left(\pi^{*}\right)$ & $\begin{array}{c}\text { Pseudo } \\
R^{2}\end{array}$ \\
\hline $\begin{array}{l}\text { Consensus } \\
\text { forecasts }\end{array}$ & 1993-00 & 27.82 & 0.01 & 0.31 & 0.01 & 10.37 & 0.05 & 0.96 \\
\hline $\begin{array}{l}\text { Consensus } \\
\text { forecasts }\end{array}$ & 1997-04 & 3.87 & 0.01 & 0.36 & 0.01 & 6.39 & 0.05 & 0.96 \\
\hline $\begin{array}{l}\text { Consensus } \\
\text { forecasts }\end{array}$ & 2001-08 & 10.96 & 0.03 & 0.75 & 0.03 & 4.90 & 0.04 & 0.97 \\
\hline $\begin{array}{l}\text { Consensus } \\
\text { forecasts }\end{array}$ & 2005-12 & 15.32 & 0.02 & 1.40 & 0.02 & 5.05 & 0.02 & 0.99 \\
\hline $\begin{array}{l}\text { Consensus } \\
\text { forecasts }\end{array}$ & 2010-17 & 7.34 & 0.02 & 0.51 & 0.02 & 5.68 & 0.02 & 0.99 \\
\hline BER analysts & $2001-08$ & 3.74 & 0.03 & 0.83 & 0.03 & 5.40 & 0.01 & 0.96 \\
\hline BER analysts & $2005-12$ & 4.86 & 0.03 & 1.17 & 0.03 & 5.21 & 0.02 & 0.99 \\
\hline BER analysts & $2010-17$ & 1.53 & 0.02 & 0.63 & 0.02 & 5.50 & 0.01 & 0.99 \\
\hline BER businesses & $2001-08$ & 0.66 & 0.01 & 0.20 & 0.01 & 7.04 & 0.04 & 0.96 \\
\hline BER businesses & $2005-12$ & 8.13 & 0.02 & 0.34 & 0.02 & 6.79 & 0.04 & 0.98 \\
\hline BER businesses & $2010-17$ & 3.93 & 0.01 & 0.28 & 0.01 & 6.90 & 0.03 & 1.00 \\
\hline BER trade unions & 2001-08 & 555.74 & 0.02 & 0.12 & 0.02 & 7.14 & 0.04 & 0.98 \\
\hline BER trade unions & $2005-12$ & 25.45 & 0.03 & 0.43 & 0.03 & 7.31 & 0.05 & 0.98 \\
\hline BER trade unions & $2010-17$ & 827.23 & 0.01 & 0.06 & 0.01 & 6.78 & 0.05 & 0.99 \\
\hline
\end{tabular}

We also assess how well our model fits by constructing a pseudo $R^{2}$ statistic, as follows:

Pseudo $R^{2}=1-\frac{\sum_{t, h} e(t, t-h)^{2}}{\sum_{t, h} f(t, t-h)^{2}}$.

This is a simple measure of the share of the variability of the forecasts that is explained by the model. By this metric, the model fits the data very well, with the $R^{2}$ exceeding 0.95 for all models. Note, however, that even restricted versions of the model result in relatively high pseudo $R^{2}$ 's. The average $R^{2}$ in the above table is 0.98 . When we compute the variability that is explained simply by lagged inflation or the estimated inflation anchor (corresponding to $\alpha(h)=0$ or $\alpha(h)=1$ ), we get average pseudo $R^{2}$ 's of 0.92 and 0.94 respectively. ${ }^{13}$

To assess our estimation results, as they pertain to inflation anchoring, we use graphical analysis. We focus on two ways to assess anchoring within our empirical framework: (A) the weight on the implicit anchor in explaining inflation expectations (a higher weight at a given horizon implies more tightly anchored expectations) and (B) the level of the implicit anchor, especially in relation to the stated inflation target of the central bank.

\footnotetext{
13 To further illustrate the fit of the model, Figure A1 in the appendix displays the forecasts, fitted values and model errors for the different BER expectations for the final rolling sample of 2010-17.
} 


\section{The Weight on the Implicit Anchor in Explaining Inflation Expectations}

We first discuss how the weight on the anchoring for different forecast horizons-given by equation (2)-changed across different sample periods. Then, we examine one- and two-year horizon forecasts across different sample periods.

\section{Different Forecast Horizons}

\section{Consensus Forecasts}

Estimates using Consensus Forecasts show an improvement in anchoring over the sample. Figure 5 displays the weight on the implicit anchor for analysts for different forecast horizons up to 24 months, and for five different sample periods, from 1993-00 to 2010-17. Overall, the line moved up over the sample period, especially at longer horizons, indicating an improvement in anchoring, especially following the introduction of IT (from the red broken line to the red solid line). In other words, our estimates indicate that forecasters were placing larger weights on the implicit anchors, and smaller weights on realised inflation, when forecasting inflation once IT was introduced. There was a subsequent decline in the anchoring of shorter horizons forecasts (from the solid red line to the dotted blue lines). Higher inflation volatility in the early 2000 s, when the rand depreciated sharply, and around the time of the GFC in the late 2000s, appears to have contributed to the reduction in anchoring. Even then, the longest horizon forecasts remained well anchored. Finally, in our latest rolling sample, anchoring improved again (from the broken blue lines to the solid blue line), around the time that realized inflation settled at around the upper end of the inflation target range.

Figure 5. Weight on Anchor Over Different Forecast Horizons, Consensus Forecasts

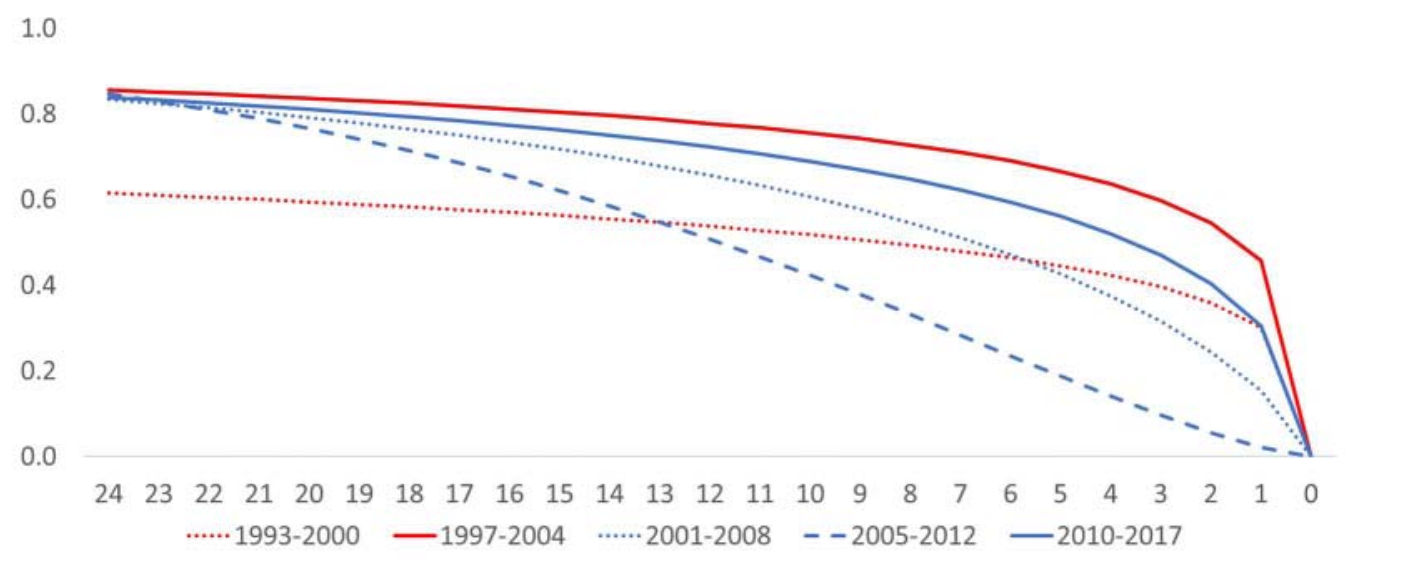

Source: Authors' calculations.

Note: Vertical axis is the value of $\alpha(h)$, which is the weight on the anchor in equation $(1) ;(1-\alpha(h))$ is the weight on current inflation. Horizontal axis is the forecast horizon $h$, measured in months before the completion of the calendar year being forecast.

\section{BER Inflation Expectations Survey}

Estimates using BER survey data also generally indicate some improvement in the degree of anchoring over our sample, although there is considerable variation in the estimates across 
the different types of forecasters (Figure 6). Focusing first on analysts, moving from the earliest rolling sample to the middle one, there was a small deterioration in the degree of anchoring that roughly coincides, in terms of degree and timing, with what we saw for the consensus forecasts above. This is perhaps not surprising given that the analysts surveyed by the BER are likely to be the most alike the forecasters in the Consensus database. ${ }^{14}$

Figure 6. Weight on Anchor Over Different Forecast Horizons, BER Expectations

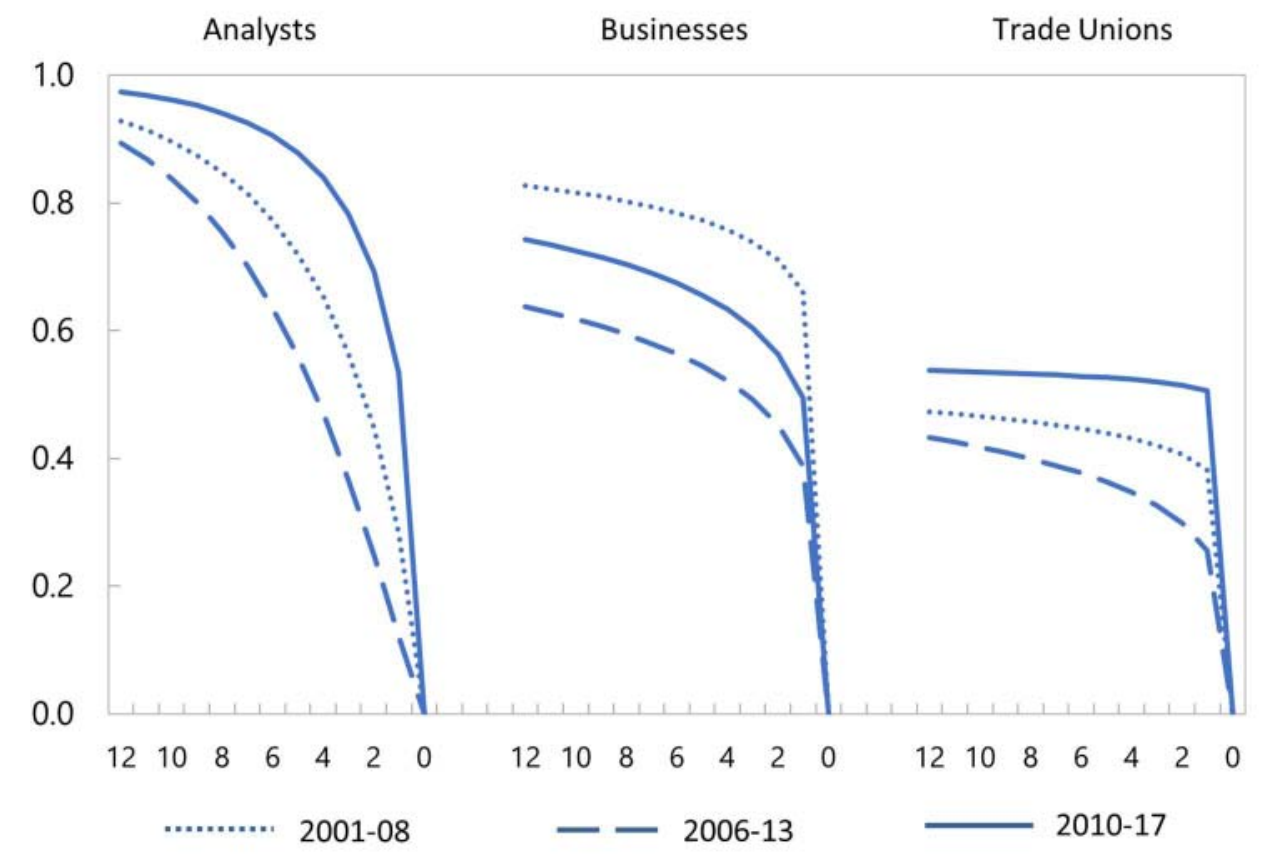

Source: Authors' calculations.

Note: Vertical axis is the value of $\alpha(h)$, which is the weight on the anchor in equation $(1) ;(1-\alpha(h))$ is the weight on current inflation. Horizontal axis is the forecast horizon $h$, measured in quarters before the completion of the calendar year being forecast.

By contrast with analysts, the expectations of businesses and trade unions are not as strongly anchored. Qualitatively, all present similar dynamics in the sense that anchoring deteriorates between the early and middle rolling samples before recovering by the end. But whereas businesses' expectations are most strongly anchored in the earliest rolling samples, trade unions' expectations are most anchored in the latest ones. One possible explanation for the qualitative similarities between businesses and trade unions is that they are on opposite sides of wage negotiations, so are responding to similar information (particularly related to wage developments), and to each other, when forming their expectations of future inflation.

\footnotetext{
14 The responders to the Consensus survey for South Africa are disproportionately analysts working for financial institutions along with smaller numbers of forecasters representing rating agencies and think tanks.
} 


\section{Focusing on one- and two-year horizon forecasts}

\section{Consensus Forecasts}

As another way to assess the degree of anchoring, we focus on the weights at the 12 and 24-month (or equivalently 4 and 8 quarter) horizons on the anchors for all years (Figure 7). Using Consensus Forecasts, anchoring at the 24-month horizon increased in the early part of the sample, as the number of years of IT within the rolling sample increased, and remained relatively stable, suggesting that this dimension of anchoring has not changed substantially. However, anchoring at the 12-month horizon worsened notably in 2005-12, consistent with earlier discussion of inflation developments during this period. Also, anchoring weakened somewhat towards the end of the sample.

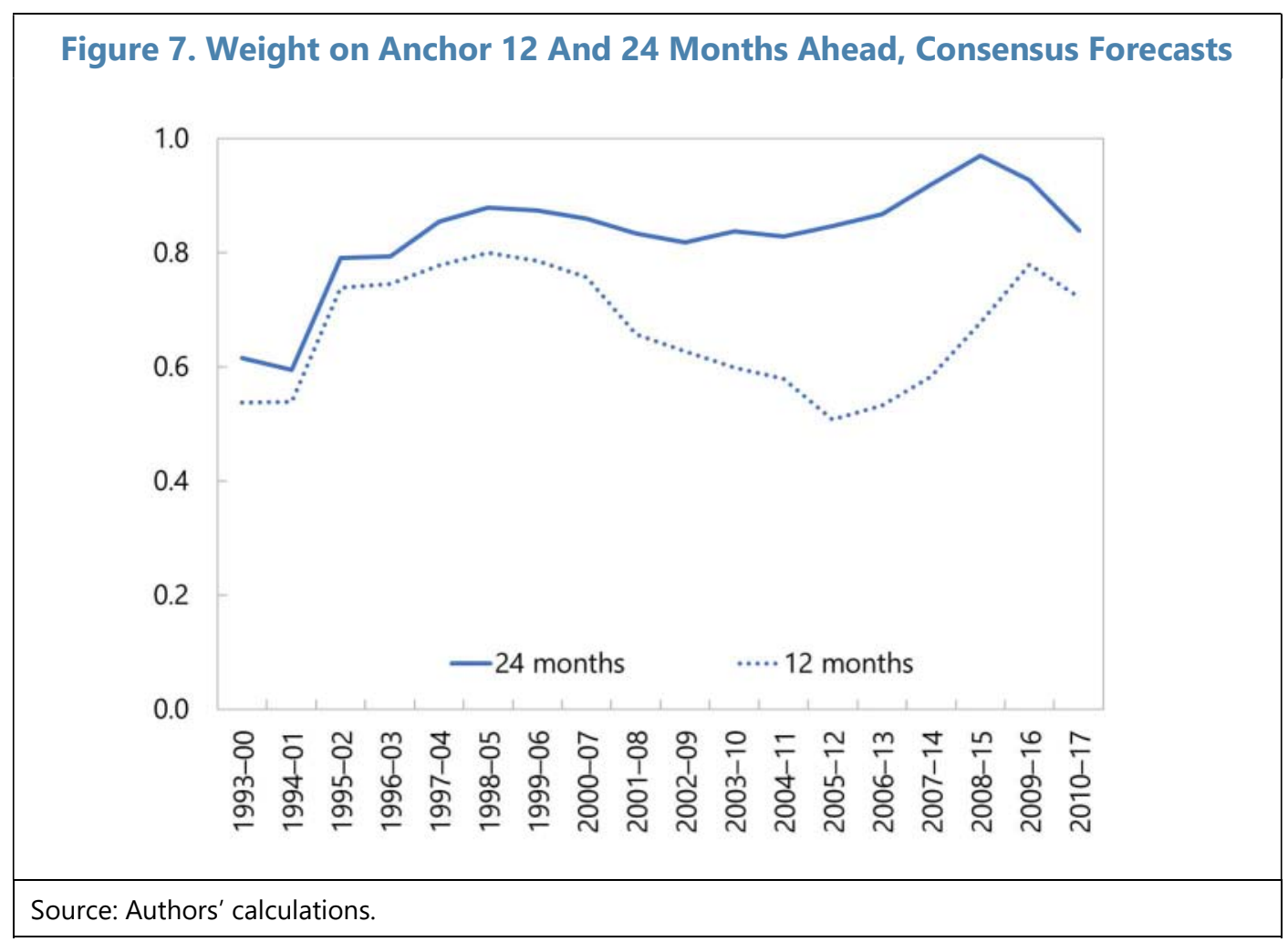

\section{BER Inflation Expectations Survey}

Estimates using BER forecasts show that analysts have consistently had the most tightly anchored expectations at the eight-quarter horizon (Figure 8). But, at the four-quarter horizon, businesses had more tightly anchored expectations than analysts until recently. One possible interpretation of this is that analysts devoted more resources to forecasting inflation at shorter horizons, and hence these forecasts tended to be more responsive to inflation developments. By contrast, if businesses paid less attention to short-term developments, their forecasts would be biased towards average outcomes, which are likely to be highly correlated with estimated anchors. Trade unions tend to exhibit the least degree of anchoring by this metric at both horizons. 


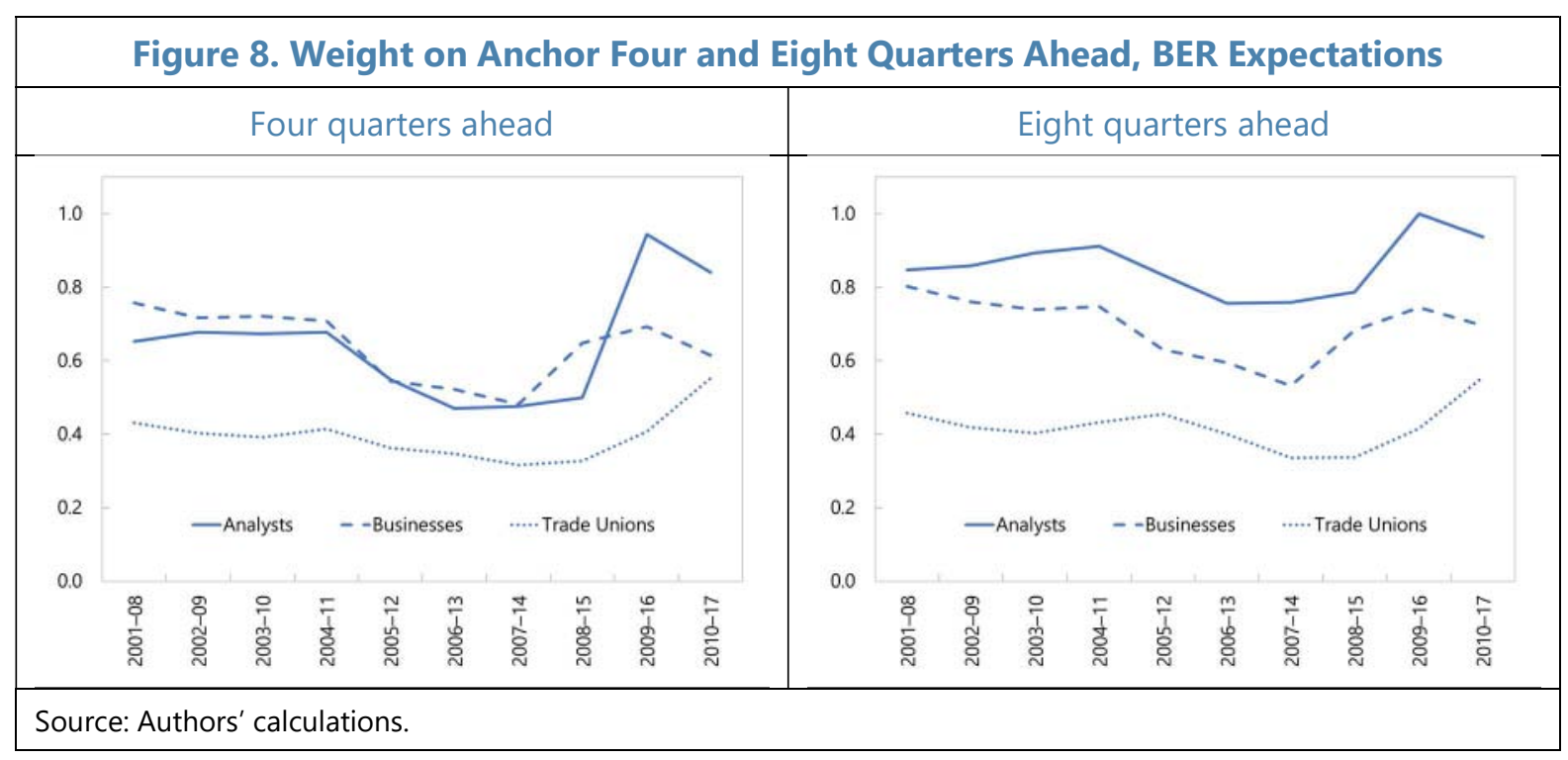

\section{The Implicit Inflation Anchor}

\section{Consensus Forecasts}

The implicit anchor estimated using Consensus Forecasts displays a significant decline up until around 2002-09, and then a slight increase (Figure 9). It fell from around 10 percent in 1993-00 to around 6 percent, the upper end of the target range, in 1998-06. During this period, inflation outcomes declined from around 15 percent to within the 3-6 percent official target range, despite volatility remaining large. The estimated anchor continued to decline to around 5 percent in 2000-07 and remained at that level through 2005-12. Subsequently, the estimated anchor rose closer to 6 percent as inflation surged to near 12 percent in 2008 and remained at around the upper end of the target range in following rolling samples.

\begin{tabular}{|l|l|}
\hline Figure 9. Estimated Inflation Anchor Using Consensus Economics Forecasts \\
(Percent)
\end{tabular}




\section{BER Inflation Expectations Survey}

Using the BER series, the estimated anchors vary significantly across the different types of forecasters (Figure 10). They are roughly 5-5.5 percent, below the upper end of the target range, for analysts. This level is similar to the estimates obtained using Consensus Forecasts. By contrast, the estimated anchors based on the forecasts of both businesses and trade unions lie above the target range. They are 6.5-7 percent for businesses, and 7-8 percent for trade unions. Our findings are similar to those of Kabundi et al (2015) estimated for analysts ( 5.4 percent) and businesses ( 6.8 percent) but above theirs for trade unions ( 6.6 percent). The anchor for businesses declined over early rolling samples, but started to trend up beginning 2004-11. For trade unions, there is a positive trend across early rolling samples. One possibility is that there is a feedback loop between the inflation expectations of these two types of forecasters: wage demands reflect the anchors of the trade unions and these subsequently affect firms' views on future price increases. The anchor for trade unions exhibits a notable fall in the final few rolling samples, down some 1.5 percentage points to around 6.5 percent. This coincided with a deterioration in economic growth which may have dented prospects for strong wage growth. ${ }^{15}$

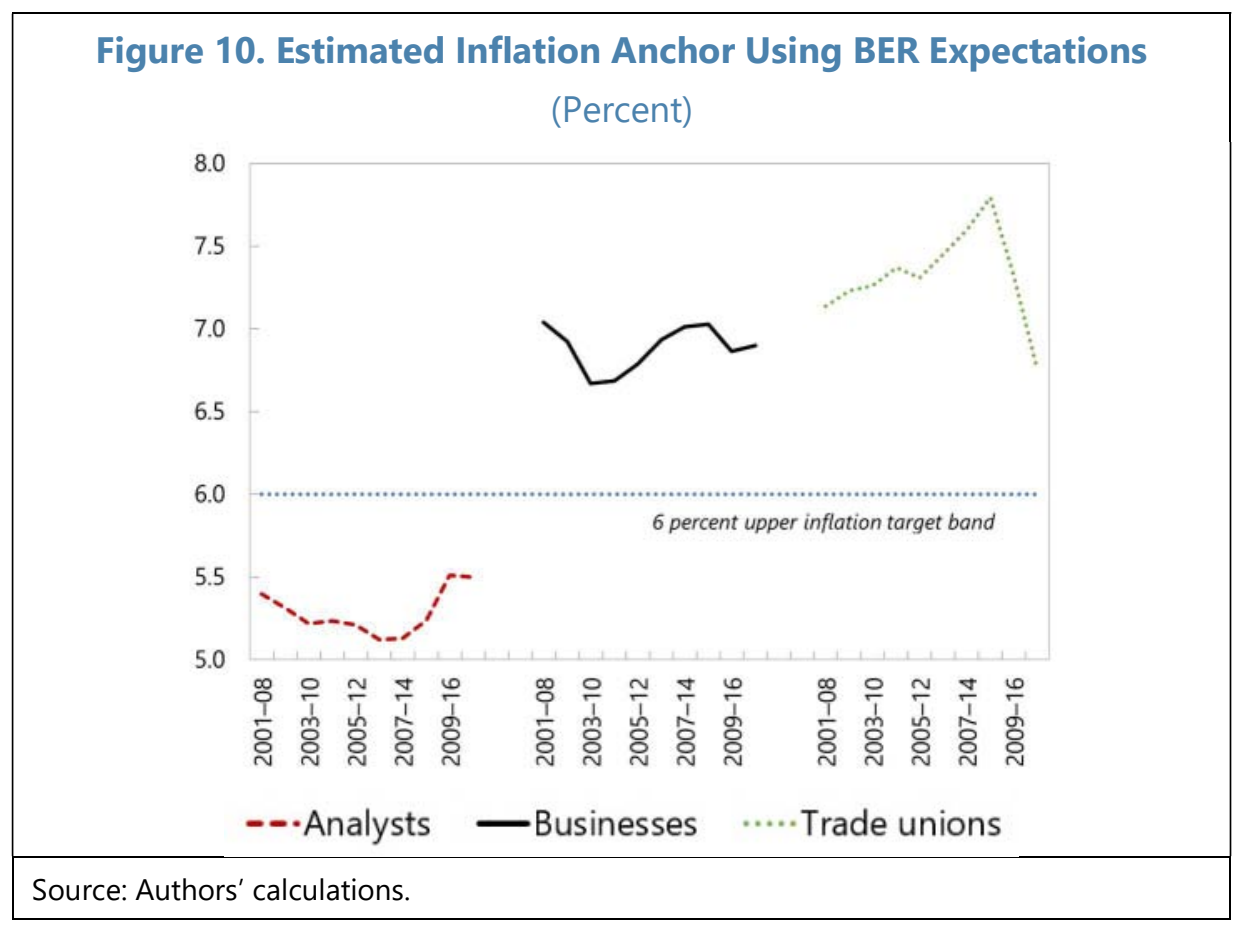

\footnotetext{
${ }^{15}$ As a robustness check, we also repeated the analysis using forecaster-level data by type, with one observation for each forecaster for each horizon where available. Because this is a highly unbalanced panel, with some forecasters only present in the panel for a short period, we impose the same parameter values across all forecasters (of a given type). In addition, we do not take into account the covariances across the different forecasters and forecast horizons when computing the coefficients of interest. The estimates are broadly consistent with those reported above: the estimated anchor for analysts remains below the upper end of the target range and the tightness of the estimates improved over time, while those for businesses and trade unions are above the target range, and above those of analysts. However, our estimated anchors for businesses are somewhat above those for trade unions, suggesting that the difference in anchoring between businesses and trade unions that we observed based on median forecasts may not be robust.
} 
To better understand what is behind these results, we constructed the mean squared error (MSE) of the inflation forecasts of each of the types of agents for the full sample and also for sub-samples reflecting the pre-GFC period (2003-07) and the post-GFC period (2010-2017). These are displayed in Figure 11. The graph makes clear that analysts do a much better job of forecasting inflation than either businesses or trade unions, and the gap between them, in a proportionate sense, widened after the GFC. Forecast performance improved for all agents from the pre- to post-GFC period, but seemingly less so for businesses and trade unions. One possibility is that analysts, for whom following inflation is a (relatively) larger part of their job, changed their inflation expectations much more dramatically in response to the reduction in inflation volatility (Figure 1), and became much more accurate, while businesses and trade unions, for whom changes in inflation are likely to attract less attention, reacted less. If so, perhaps this gap will narrow over time, as businesses and trade unions continue to update their views of the inflation process.

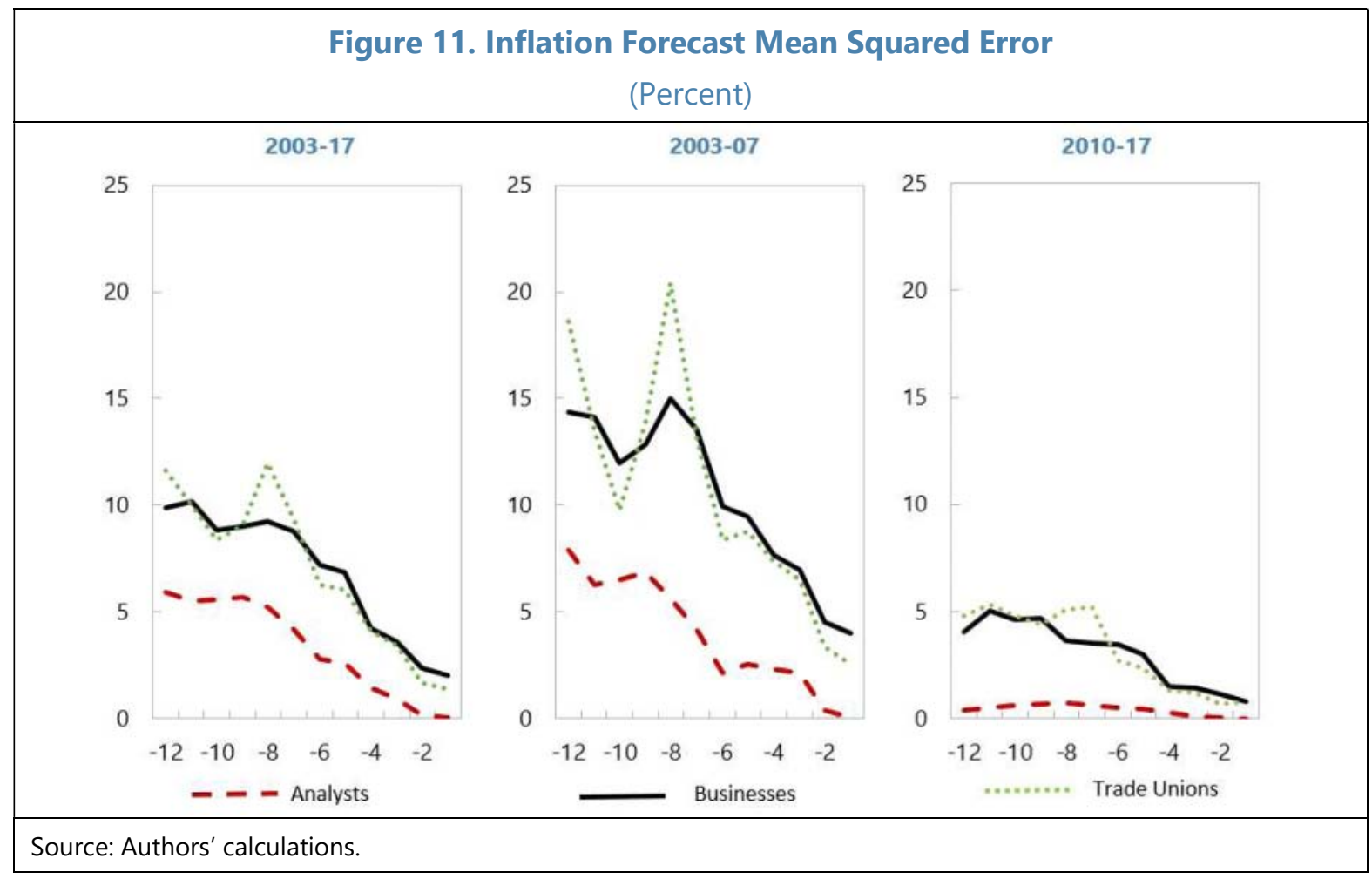

\section{CONCLUDING DISCUSSION}

Maintaining low and stable inflation helps enhance central bank credibility and anchor inflation expectations. Our results suggest that, overall, inflation expectations have become more strongly anchored in South Africa in recent years, at levels around the upper end of the official target range of 3-6 percent. However, the inflation expectations of agents involved in setting wages and prices-that is, businesses and trade unions-are anchored to levels above the official target rage.

We offer two complimentary explanations for this disparity. First, because businesses and trade unions are likely to interact with each other during the setting of wages, it is possible 
that their expectations influence each other. Second, analysts, for whom following inflation may be a relatively more important part of their job, may update their inflation expectations more efficiently than other agents in response to changes in the economy, including the introduction of IT. By contrast, businesses and trade unions may be influenced more strongly by inflation outturns, which may receive more media attention than changes to the monetary policy framework.

If this is the case, then our results illustrate that the challenges in anchoring the expectations vary across different kinds of agents. Even once a central bank has gained credibility by anchoring the inflation expectations of analysts, South African data illustrates the possibility that agents directly involved in the setting of wages and prices that ultimately drive the inflation process may still have less firmly anchored inflation expectations. Improved anchoring of the expectations of these agents - as a result of observed inflation outcomes, central bank communications or perhaps structural reforms that support greater competition in goods markets and increase labour market flexibility - could then be expected to contribute to further improvements in inflation outcomes.

The SARB is already placing an increased focus on communications. The SARB now uses the Quarterly Projection Model as the main tool to inform decisions of the Monetary Policy Committee and publishes the results, including policy rate projections, as part of its communication policy. In the context of reduced policy and political uncertainty, the frequency of surprise monetary policy decisions has therefore declined (IMF, 2018). Recently, the SARB publicly clarified its preference to anchor inflation expectations at 4.5 percent, the mid-point of the target range. Continued and effective communication with stakeholders (Kabundi et al, 2015; Viegi, 2015), and the use of innovative methods and media for engaging with general public (Haldane and McMahon, 2018), could assist in further anchoring inflation expectations in South Africa. 


\section{REFERENCES}

Celasun, O., G. Gelos, and A. Prati. 2004. "Obstacles to disinflation: What is the role of fiscal expectations?”, Economic Policy 19(40), 442-81.

Carroll, C. D. 2003. "Macroeconomic expectations of households and professional forecasters", Quarterly Journal of economics 118(1), 269-298.

Coibion, O., Y. Gorodnichenko, and S. Kumar. 2018. "How do firms form their expectations? New survey evidence", American Economic Review, forthcoming.

Ehlers, N. and R. Steinbach. 2007. "The formation of inflation expectations in South Africa", South African Reserve Bank Working Paper 07/06.

Faust, J. and J. H. Wright. 2013. "Forecasting inflation", in Handbook of Economic Forecasting, edited by G Elliott and A Timmermann, 2, 2-56, Amsterdam: Elsevier.

Gaglianone, W. P. 2017. "Empirical findings on inflation expectations in Brazil: A survey", Banco Central do Brasil Working Papers 464.

Gürkaynak, R. S., B. Sack, and E. T. Swanson. 2005. "Do actions speak louder than words? The response of asset prices to monetary policy actions and statements", International Journal of Central Banking 1(1) 55-93.

Haldane, A. and M. McMahon. 2018. "Central bank communications and the general public", AEA Papers and Proceedings 108, 578-83.

Hattori, M. and J. Yetman. 2017. "The evolution of inflation expectations in Japan", Journal of the Japanese and International Economies 46, 53-68

International Monetary Fund. 2018. South Africa, IMF Country Report 18/246.

Isiklar, G. and K. Lahiri. 2007. "How far ahead can we forecast? Evidence from crosscountry surveys", International Journal of Forecasting 23(2) 167-87.

Kabundi, A., E. Schaling, and M. Some. 2015. "Monetary policy and heterogeneous inflation expectations in South Africa", Economic Modelling 45, 109-117

. 2016. "Estimating a time-varying Phillips curve for South Africa", South African Reserve Bank Working Paper 16/05.

Klein, N. 2012. "Estimating the implicit inflation target of the South African Reserve Bank," IMF Working Paper 12/77.

Łyziak, T. 2013. "Formation of inflation expectations by different economic agents", Eastern European Economics 51(6), 5-33.

Madeira, C. and B. Zafar. 2015. "Heterogeneous inflation expectations and learning", Journal of Money, Credit and Banking 47(5), 867-96. 
Mehrota, A. and J. Yetman. 2014a. "How anchored are inflation expectations in Asia? Evidence from surveys of professional forecasters”, BIS Papers 77, 181-191.

. 2014b. "Decaying expectations: What inflation forecasts tell us about the anchoring of inflation expectations", BIS Working Papers no 464 and International Journal of Central Banking, forthcoming.

Pierdziocha, C., Monique B. R., and R. Guptac. 2018. "On the directional accuracy of inflation forecasts: Evidence from South African survey data", Journal of Applied Statistics 45(5), 884-900.

Rossouw, J., V. Padayachee, and A. Bosch. 2011. "A comparison of inflation expectations and inflation credibility in South Africa: Results from survey data", South African Journal of Economic and Management Sciences 14(3), 263-81.

Shanno, D. 1985. "On Broyden-Fletcher-Goldfarb-Shanno method", Journal of Optimization Theory and Applications 46(1), 87-94.

Tarullo, D. 2017. "Monetary policy without a working theory of inflation", Hutchins Center Working Paper \#33.

Yetman, J. 2017. "The evolution of inflation expectations in Canada and the US", Canadian Journal of Economics 50(3), 711-737.

Viegi, N. 2015. "Labour market and monetary policy in South Africa", South African Reserve Bank Working Paper 15/01. 
Figure A1. Actual and fitted BER inflation expectations and model error, 2010-17 (Percent)

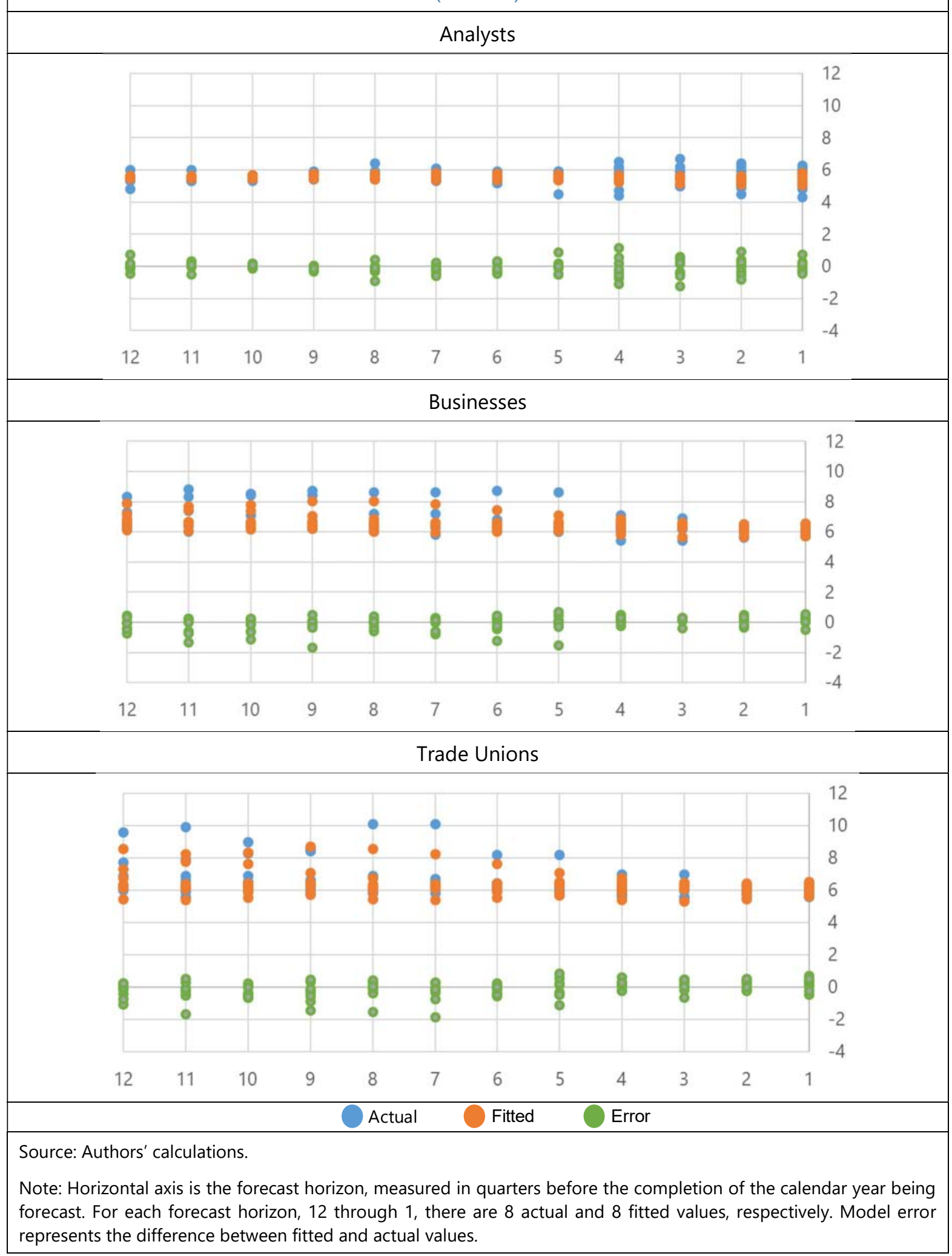

